\title{
Waterhouse-Friderichsen Syndrome
}

National Cancer Institute

\section{Source}

National Cancer Institute. Waterhouse-Friderichsen Syndrome. NCI Thesaurus. Code C85225.

A serious disorder characterized by massive adrenal gland hemorrhage secondary to a bacterial infection, most often Neisseria meningitidis infection. It is manifested with decreased blood pressure, shock, disseminated intravascular coagulation, and adrenocortical insufficiency. 